\title{
Prevalence of hepatitis B and C infection in persons living with HIV enrolled in care in Rwanda
}

\author{
Justine Umutesi ${ }^{1}$, Bryony Simmons ${ }^{2}$, Jean D. Makuza ${ }^{1}$, Donatha Dushimiyimana', Aimable Mbituyumuremyi ${ }^{1}$,
} Jean Marie Uwimana ${ }^{1}$, Nathan Ford ${ }^{3}$, Edward J. Mills ${ }^{4}$ and Sabin Nsanzimana ${ }^{1,5,6^{*}}$

\begin{abstract}
Background: Hepatitis B (HBV) and C (HCV) are important causes of morbidity and mortality in people living with human immunodeficiency virus (HIV). The burden of these co-infections in sub-Saharan Africa is still unclear. We estimated the prevalence of the hepatitis B surface antigen ( $\mathrm{HBsAg}$ ) and hepatitis C antibody (HCVAb) among HIV-infected individuals in Rwanda and identified factors associated with infection.

Methods: Between January 2016 and June 2016, we performed systematic screening for HBsAg and HCVAb among HIV-positive individuals enrolled at public and private HIV facilities across Rwanda. Results were analyzed to determine marker prevalence and variability by demographic factors.

Results: Overall, among 117,258 individuals tested, the prevalence of HBsAg and HCVAb was 4.3\% (95\% confidence interval [Cl] (4.2-4.4) and 4.6\% (95\% Cl 4.5-4.7) respectively; 182 (0.2\%) HIV+ individuals were co-infected with $\mathrm{HBsAg}$ and HCVAb. Prevalence was higher in males (HBsAg, 5.4\% [5.1-5.6] vs. 3.7\% [3.5-3.8]; HCVAb, 5.0\% [4.8-5.2] vs. 4.4\% [4.3-4.6]) and increased with age; HCVAb prevalence was significantly higher in people aged $\geq 65$ years (17.8\% [16.4-19.2]). Prevalence varied geographically.

Conclusion: HBV and HCV co-infections are common among HIV-infected individuals in Rwanda. It is important that viral hepatitis prevention and treatment activities are scaled-up to control further transmission and reduce the burden in this population. Particular efforts should be made to conduct targeted screening of males and the older population. Further assessment is required to determine rates of HBV and HCV chronicity among HIV-infected individuals and identify effective strategies to link individuals to care and treatment.
\end{abstract}

Keywords: HIV, Hepatitis, Co-infection, Prevalence

\section{Background}

Viral hepatitis has emerged as an important public health issue globally, characterised by high prevalence, a high burden of morbidity and mortality, and suboptimal diagnosis and management approaches [1,2].

Viral hepatitis disproportionately affects persons living with human immunodeficiency virus (HIV) [3, 4]. While varying in their transmission efficiency, HIV, hepatitis B (HBV), and hepatitis $\mathrm{C}(\mathrm{HCV})$ share common routes of

\footnotetext{
*Correspondence: nsabinco@gmail.com

${ }^{1}$ HIV/AIDS \& STIs Diseases Division, Rwanda Biomedical Centre, Kigali,

Rwanda

${ }^{5}$ Basel Institute for Clinical Epidemiology and Biostatistics, University Hospital

Basel, Basel, Switzerland

Full list of author information is available at the end of the article
}

transmission, and as such, prevalence is generally higher in HIV-infected individuals [3-5]. To compound this, HIV infection accelerates the natural course of HBV and $\mathrm{HCV}$, promoting faster progression to chronicity, liver fibrosis, and malignancy [4, 6, 7]. As antiretroviral therapy (ART) programmes have matured and people with HIV survive longer, viral hepatitis has become a major cause of death in HIV-infected individuals [8].

Sub-Saharan Africa (SSA) has the highest burden of infectious diseases and remains the epicentre of the global HIV epidemic $[9,10]$. Despite this, epidemiological data for HBV and HCV are lacking due to limited diagnostic capacity and a lack of prioritisation in public health programmes. Available data suggest widely variable rates 
of $\mathrm{HBV}$ and $\mathrm{HCV}$ infection in HIV-infected populations across SSA. In one meta-analysis, HIV/HBV frequency in SSA varied from $0 \%$ to $28.4 \%$ (median $7.8 \%$ ) [11]. Two recent systematic reviews suggest an overall $\mathrm{HCV}$ prevalence of 3\% among people living with HIV in SSA with significant regional variations $(0-55.9 \%)[3,12]$.

Data from Rwanda is limited. Among 402 HIVinfected, ART naïve individuals recruited from a major Kigali-based urban healthcare facility, a 5.2\% hepatitis B surface antigen (HBsAg) and a 5.7\% hepatitis C antibody (HCVAb) prevalence were reported [13]. The HBsAg and HCVAb prevalence were $2.4 \%$ and $4.9 \%$, respectively, in 82 samples retrospectively analysed from HIVpositive pregnant women in 2004 [14]. A systematic review estimated the prevalence of HCVAb in persons living with HIV was estimated to be less than $3 \%$ in Rwanda [3]. Given the paucity of epidemiological data from robust studies, there is a need for nationally representative estimates to ascertain the scope of the viral hepatitis burden among HIV-positive individuals in Rwanda.

Advances in prevention and treatment have facilitated the development of public health programmes to control viral hepatitis in resource limited settings [15, 16]. Rwanda has been one of the first countries in SSA to establish a viral hepatitis control programme. Initiated in 2012 and building on the existing HIV infrastructure, the programme was intensified in 2015 with the arrival of new efficacious treatments for HCV [17]. As part of routine programme implementation, an initiative to screen all HIV-positive individuals enrolled into care for key markers for HBV and HCV was implemented from January to June 2016, reaching approximately 120,000 HIV-infected individuals nationwide.

The present study set out to characterise the prevalence and characteristics of HBsAg and HCVAb in HIVpositive individuals in Rwanda using data collected through this screening programme. Our data provide a picture of HBV and HCV co-infection with HIV in a setting where resources for screening, diagnosis, and treatment are limited. Findings will be fundamental for informing future policy and decision-making in Rwanda.

\section{Methods}

\section{Study objectives}

The primary objective of this study was to quantify the prevalence of HBsAg and HCVAb in HIV-positive individuals enrolled into care using data collected during a national screening activity. Secondary objectives were to analyse data by subgroups.

\section{Data collection}

Data were obtained from the nationally representative electronic database compiled throughout the screening activity conducted between January and June 2016. The programme targeted all individuals with HIV nationwide, enrolling individuals at all public and private health facilities providing HIV services across Rwanda (approximately 500 facilities). Screening was offered free-of-charge to all HIV-positive individuals enrolled in care at a routine appointment, regardless of ART status. HIV-positive individuals are followed up monthly at health facilities and as such, all eligible individuals had the opportunity to undergo screening during the implementation period. All HIV-positive individuals screened were included in the database which captures demographic data, HIV infection and disease characteristics, and $\mathrm{HBV}$ and $\mathrm{HCV}$ clinical test results.

In brief, testing procedures were as follows: individuals were invited for screening during a routine HIV appointment, specimens were collected at the site of enrolment, and samples transported to a testing facility. Testing was performed at 13 sites across Rwanda using Murex enzyme-linked immunosorbent assays (ELISA) for HBsAg (version 3.0) and HCVAb (version 4.0; DiaSorin S.p.A, Italy). All testing was supervised by a team of laboratory technicians from the National Reference Laboratory.

The database was de-identified for the present study and no persons involved in the analysis of data were able to access the linked database. For comparison, aggregate population data for HIV-infected individuals were obtained from the Rwanda national HIV health record system (TRACnet) and were correct as of June 2016.

\section{Statistical methods \& data analysis}

Sample weighting was applied in all analyses to ensure results were nationally representative of people with HIV enrolled into care in Rwanda. The post-stratification weights were calculated using known age, gender, and ART distributions. All continuous variables were categorised for analysis based on appropriate thresholds.

Descriptive statistics were performed for all variables. National prevalence estimates for HBV (HBsAg) and $\mathrm{HCV}$ (HCVAb) were calculated and presented with the corresponding 95\% confidence intervals (95\% CIs). HBsAg and HCVAb prevalence by demographic and HIV characteristics were determined; bivariate associations were tested using Pearson's chi-square tests. All analyses were performed using Stata software (version 12.0; StataCorp, Texas, USA).

\section{Ethics}

The routinely collected programme data analysed for this study are maintained by the Rwanda Biomedical Centre (RBC), Division of HIV/AIDS, STIs and Other Blood Borne Infections; the ethical procedures for the collection of these data are governed by the Medical Research Council of Rwanda. Secondary analyses of routinely collected data are exempt by the Rwanda 
Ethics Committee for routine program implementation activities conducted by the RBC, as was the case in this analysis.

\section{Results}

Testing coverage and population characteristics

A total of 117,258 HIV-positive individuals were screened between January and June 2016 and were included in the present analysis. This corresponds to a coverage level of $64.9 \%$ of the total HIV population enrolled to care at facilities across Rwanda. The characteristics of the screened population did not differ significantly from the overall HIV-positive population enrolled to care.

Table 1 describes the socio-demographic and HIV characteristics of the included individuals. The majority of the population were female (65.1\%), aged 35-54 years (56.0\%), and lived in rural areas (75.0\%). Most individuals were enrolled at the health centre or clinic level (84.3\%); $15.7 \%$ were enrolled at the tertiary hospital level, inclusive of district, provincial, and referral hospitals. Over $90 \%$ of individuals were on ART at the time of screening.

\section{Prevalence}

The overall HBsAg and HCVAb prevalence in the HIVinfected population and the prevalence by sociodemographic and HIV characteristics are shown in Table 1.

\section{HBV prevalence}

In total, HBsAg result were available for 114,040 / 117,258 (97.3\%) individuals included in the database. Overall, 4876/114,040 individuals were HBsAg positive. The unadjusted and adjusted prevalence of HBsAg were equal at $4.3 \%$ (95\% CI 4.2-4.4\%). Prevalence was significantly higher in males compared with females $(5.4 \%$ [95\% CI 5.1-5.6\%] vs. 3.7\% [95\% CI 3.5-3.8\%]). Prevalence varied by age group and was lowest in individuals less than 15 years of age (2.1\% [95\% CI 1.7-2.6\%]). HBsAg prevalence was slightly higher at hospital enrolment compared with enrolment at primary care level (health centres and clinics). By geographical region, prevalence was highest in the Eastern province $(5.5 \%$ [95\% CI $5.2-5.8 \%])$ and in the City of Kigali (5.0\% [95\% CI 4.7-5.3\%]); prevalence was significantly higher in urban areas compared with rural areas $(4.9 \%$ [95\% CI $4.7-5.2 \%$ ] vs. $4.0 \%$ [95\% CI $3.9-4.2 \%]$ ). Prevalence by district is shown in (Fig. 1); prevalence varied from $10.7 \%$ (Bugesera) down to $2.1 \%$ (Ngororero).

\section{HCV prevalence}

In total, HCVAb results were available for 116,868 / 117,258 (99.7\%) individuals included on the database. For HCVAb, 5470/116,868 individuals were found to be positive. The unadjusted prevalence was $4.7 \%$ (95\% CI 4.5-4.8\%) and the adjusted prevalence was $4.6 \%$ (95\% CI 4.5-4.7\%). Like HBsAg, prevalence was higher in males than females (5.0\% [95\% CI 4.8-5.2\%] vs. 4.4\% [4.3-4.6\%]). Prevalence increased with age, and was significantly higher in individuals aged 55-64 (8.8\% [95\% CI 8.3-9.3\%]) and those aged 65 or over (17.8\% [95\% CI 16.4-19.2\%]). Prevalence was slightly higher at hospitals compared with primary care facilities $(5.0 \%$ [95\% CI $4.7-5.3 \%]$ vs. $4.5 \%$ [95\% CI 4.4-4.7\%]). HCVAb prevalence was highest in the Southern (5.9\% [95\% CI 5.6-6.2\%]) and Eastern (5.2\% [95\% CI 4.9-5.5\%]) provinces of Rwanda. In contrast to HBsAg prevalence, HCVAb prevalence was higher in rural areas (4.7\% [95\% CI 4.5-4.8\%]) than urban areas (4.3\% [95\% CI 4.0-4.6]); however, this difference was not significant. Prevalence of HCVAb by district is shown in Fig. 1; HCVAb prevalence varied from $8.4 \%$ (Gisagara) to $2.7 \%$ (Rutsiro) and was generally higher in districts bordering other countries.

\section{Co-infection}

Of 117,258 individuals included in the database, 113,681 (96.9\%) had results for both HBsAg and HCVAb. A total of 182/113,681 individuals were coinfected with $\mathrm{HBsAg}$ and HCVAb, corresponding to an adjusted co-infection prevalence of $0.2 \%$ ( $95 \%$ CI $0.1-0.2 \%$ ).

\section{Discussion}

Advances in treatment and the benefits of early detection have validated the scale-up of viral hepatitis screening efforts in resource-limited settings $[15,18]$. Accordingly, a national programme was recently conducted in Rwanda to screen all persons with HIV for key $\mathrm{HBV}$ and $\mathrm{HCV}$ markers. The high screening uptake, reaching almost 120,000 individuals, demonstrates that large regional or national screening programmes for viral hepatitis are feasible among HIV population in resource-limited settings. Given the limited resources available for population screening efforts, the present study aimed to analyse the results to contribute towards the understanding of the viral hepatitis co-infection burden in Rwanda and to guide prioritisation for testing of key at-risk and geographic populations.

Our study estimates the prevalence of HBsAg among HIV-infected individuals to be $4.3 \%$. This is consistent with other studies conducted in Rwanda and should be considered a robust estimate given the large sample size $[13,14]$. Due to the cross-sectional nature of this study, we were unable to verify the persistence of HBsAg over time; HBsAg is a good proxy for chronicity and we assume that HBsAg-positivity represents chronic infection. In accordance with the Rwanda viral hepatitis treatment guidelines, all individuals positive for $\mathrm{HBsAg}$ will be initiated on tenofovir-based ART. 
Table 1 Baseline characteristics and prevalence of HBsAg and HCVAb by demographics and HIV characteristics

\begin{tabular}{|c|c|c|c|c|c|c|}
\hline \multirow{3}{*}{$\overline{\text { Overall }}$} & \multicolumn{3}{|c|}{$\operatorname{HBsAg}(n=114,040)$} & \multicolumn{3}{|c|}{$\operatorname{HCVAb}(n=116,868)$} \\
\hline & \multirow[t]{2}{*}{ Total (\%) } & \multirow[t]{2}{*}{ Positive $(95 \% \mathrm{Cl}$ ) } & \multirow[t]{2}{*}{$p$-value ${ }^{a}$} & \multirow[t]{2}{*}{ Total (\%) } & \multirow[t]{2}{*}{ Positive (95\% Cl) } & \multirow[t]{2}{*}{$p$-value ${ }^{a}$} \\
\hline & & & & & & \\
\hline & 114,040 & $4.3(4.2-4.4)$ & & 116,868 & $4.6(4.5-4.7)$ & \\
\hline \multicolumn{7}{|l|}{ Demographic factors } \\
\hline Age & & & $<0.005$ & & & $<0.005$ \\
\hline$<15$ & $4917(4.4)$ & $2.1(1.7-2.6)$ & & $5062(4.4)$ & $1.7(1.3-2.1)$ & \\
\hline $15-24$ & 7409 (6.6) & $4.0(3.5-4.4)$ & & $7616(6.6)$ & $2.1(1.7-2.4)$ & \\
\hline $25-34$ & $21,287(19.0)$ & $4.2(3.9-4.5)$ & & $21,838(19.0)$ & $3.1(2.9-3.4)$ & \\
\hline $35-44$ & $34,113(30.4)$ & $4.8(4.5-5.0)$ & & $34,971(30.5)$ & $3.8(3.5-4.0)$ & \\
\hline $45-54$ & $28,719(25.6)$ & $4.5(4.2-4.7)$ & & 29,371 (25.6) & $4.7(4.5-5.0)$ & \\
\hline $55-64$ & $12,582(11.2)$ & $4.0(3.6-4.4)$ & & $12,871(11.2)$ & $8.8(8.3-9.3)$ & \\
\hline$\geq 65$ & $3037(2.7)$ & $3.9(3.2-4.6)$ & & $3098(2.7)$ & $17.8(16.4-19.2)$ & \\
\hline Gender & & & $<0.005$ & & & $<0.005$ \\
\hline Female & $74,141(65.1)$ & $3.7(3.5-3.8)$ & & $75,946(65.1)$ & $4.4(4.3-4.6)$ & \\
\hline Male & $39,751(34.9)$ & $5.4(5.1-5.6)$ & & 40,774 (34.9) & $5.0(4.8-5.2)$ & \\
\hline Enrolment facility & & & 0.031 & & & 0.013 \\
\hline Health center & $92,576(84.2)$ & $4.2(4.0-4.3)$ & & 94,991 (84.3) & $4.5(4.4-4.7)$ & \\
\hline Hospital & $17,346(15.8)$ & $4.5(4.2-4.9)$ & & $17,715(15.7)$ & $5.0(4.7-5.3)$ & \\
\hline \multicolumn{7}{|l|}{ Geographical factors } \\
\hline Province & & & $<0.005$ & & & $<0.005$ \\
\hline Kigali & $19,135(16.8)$ & $5.0(4.7-5.3)$ & & $19,413(16.6)$ & $4.0(3.7-4.2)$ & \\
\hline East & $23,404(20.5)$ & $5.5(5.2-5.8)$ & & $25,874(22.1)$ & $5.2(4.9-5.5)$ & \\
\hline North & $16,094(14.1)$ & $4.2(3.9-4.6)$ & & $16,114(13.8)$ & $4.2(3.9-4.6)$ & \\
\hline South & $27,368(24.0)$ & $3.6(3.4-3.9)$ & & $27,367(23.4)$ & $5.9(5.6-6.2)$ & \\
\hline West & $28,027(24.6)$ & $3.5(3.3-3.7)$ & & $28,086(24.0)$ & $3.5(3.3-3.8)$ & \\
\hline Residence $^{b}$ & & & $<0.005$ & & & 0.013 \\
\hline Rural & $73,820(74.7)$ & $4.0(3.9-4.2)$ & & $76,070(75.1)$ & $4.7(4.5-4.8)$ & \\
\hline Urban & $24,975(25.3)$ & $4.9(4.7-5.2)$ & & 25,198 (24.9) & $4.3(4.0-4.6)$ & \\
\hline \multicolumn{7}{|l|}{ HIV characteristics } \\
\hline ART category & & & 0.214 & & & $<0.005$ \\
\hline On ART & $98,974(91.6)$ & $4.3(4.2-4.5)$ & & $101,510(91.5)$ & $4.4(4.3-4.5)$ & \\
\hline Pre ART & $9119(8.4)$ & $4.1(3.6-4.5)$ & & $9381(8.5)$ & $6.6(6.1-7.1)$ & \\
\hline CD4 count ${ }^{b}$ & & & $<0.005$ & & & $<0.005$ \\
\hline$\leq 500$ & $34,698(41.2)$ & $4.9(4.7-5.1)$ & & $35,339(41.2)$ & $5.0(4.8-5.3)$ & \\
\hline$>500$ & $49,469(58.8)$ & $3.7(3.6-3.9)$ & & $50,497(58.8)$ & $4.4(4.2-4.6)$ & \\
\hline HIV viral load ${ }^{b}$ & & & $<0.005$ & & & 0.433 \\
\hline$\leq 1000$ & $66,272(95.1)$ & $3.9(3.7-4.1)$ & & $67,424(95.1)$ & $4.3(4.1-4.5)$ & \\
\hline$>1000$ & $3406(4.9)$ & $5.5(4.6-6.4)$ & & $3486(4.9)$ & $4.6(3.8-5.4)$ & \\
\hline
\end{tabular}

Results are proportion positive (95\% confidence interval); Sampling weights have been applied

${ }^{a}$ Reported are Chi-Square $p$-values; statistically significant $p$-values are in bold $(p<0.05)$

${ }^{b}$ Missing responses $\geq 10 \%$

The epidemiology of HBsAg is characterised by a higher prevalence in males, whereby males have an almost $50 \%$ greater risk of becoming HBV infected. This finding is in concordance with other studies conducted in SSA [19]. HIV/HBV coinfection patterns vary geographically from $2.1 \%$ up to $10.7 \%$ across the 30 districts of Rwanda. 


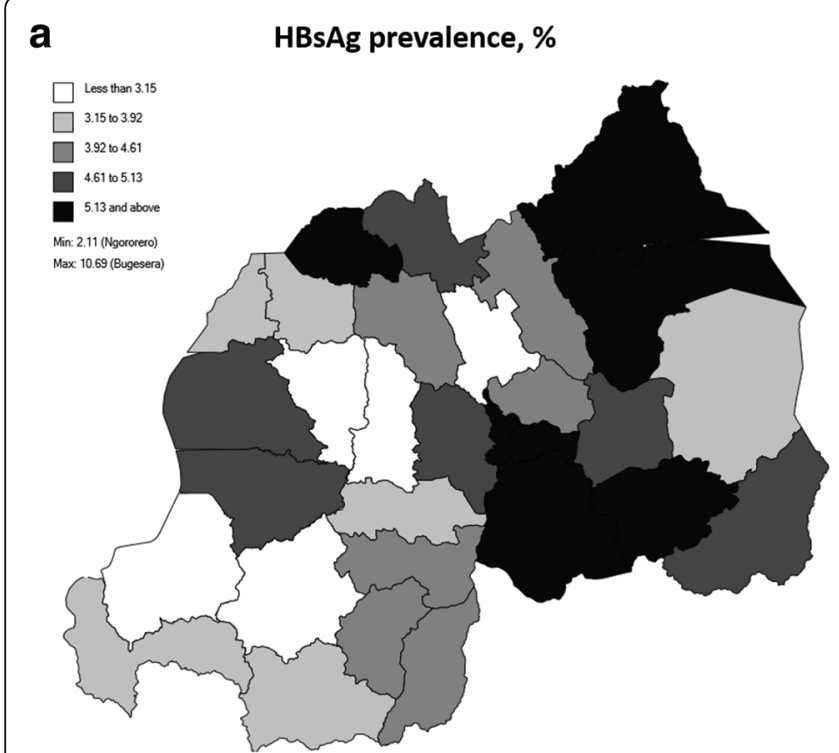

b

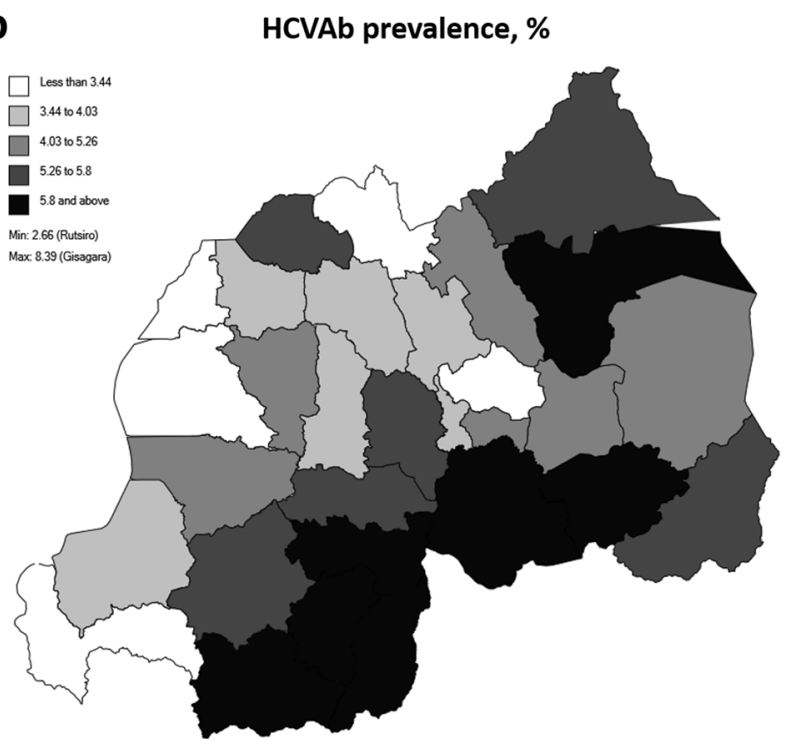

Fig. 1 Prevalence of a HBsAg and $\mathbf{b}$ HCVAb by District, Rwanda

Of note, the HBsAg prevalence is lowest in children below 15 years, motivated by the roll-out of $\mathrm{HBV}$ vaccination activities since 2002. Despite this decrease, our findings indicate that strengthening of vaccination activities is required. At present, the HBV birth-dose vaccination, administered within $24 \mathrm{~h}$ of birth is not implemented and should be considered as a strategy to reduce perinatal transmission [18]. Further, HBV vaccination in HIV-positive populations may provide a moderately lower response rate than in the general population, and as such, implementing polices with 1) specific immunisation algorithms for HIV-infected/exposed children and 2) vaccine response monitoring should be explored [19-21].

We found an HCVAb seroprevalence of $4.6 \%$ among HIV-infected individuals, marginally lower than that observed in previous studies (4.9-5.6\%) $[13,14]$. Consistent with findings from other SSA populations, HCVAb epidemiology is characterised by a higher prevalence in males, and by an increasing prevalence with the increase in age [22-25]. Cumulative exposure may explain the association between HCVAb prevalence and older age. However, given the strikingly higher prevalence in individuals over 55 years, it is likely the association is impacted by a cohort effect of patients infected many years ago. Our findings indicate that one-time screening of individuals aged over 55 should be recommended. Birthcohort screening is in practice or has been evaluated in various other settings and has largely been identified as a cost-effective initiative [26-29].

HCVAb prevalence varies geographically from $2.7 \%$ to 8.4\% across Rwanda's 30 districts and key districts in which mass screening activities should be implemented have been identified. Efforts should also be made to scale up screening in border districts where HCVAb prevalence in the HIV population has been observed to be higher than average.

The main limitation of the present study is the absence of confirmation of chronic HCV infection with HCV RNA testing. Several studies have suggested that HCV serology is prone to false-positive results, especially in HIV-infected patients in SSA where the proportion of individuals confirmed by detection of HCV RNA after a positive HCVAb test is lower than other parts of the world [12, 30, 31]. Further, HCVAb presence includes those with resolved infection and as such does not necessarily confer active infection. There is conflicting evidence surrounding viremia rate across SSA, suggesting the possibility of localised outbreaks and the need for specific data to understand endemicity [12, 30, 32-34]. Molecular characterisation is required to determine the prevalence of chronic HCV and to accurately reflect current needs for $\mathrm{HCV}$ treatment in Rwanda. Despite this, the prevalence of HCVAb is still meaningful, filling knowledge gaps on individuals more likely to become infected with HCV.

This study was further limited by its retrospective nature. Ideally, this would have been an opportunity to collate risk factors for viral hepatitis infection in Rwanda. The authors decided against a risk factor regression analysis as many key risk factors for infection were not collected and the model would have been of limited application.

\section{Conclusions}

This study adds to the understanding of viral hepatitis among HIV-infected individuals in Rwanda. The expanded 
viral hepatitis testing activity has achieved early diagnosis of individuals that will facilitate linkage to further testing and care, reducing hepatitis-related morbidity and curbing onward disease transmission. The findings presented should be used to inform policy and targeted screening activities, and should be extrapolated beyond the HIV positive population. Additional studies should be performed in HIV positive and HIV negative individuals to fill the remaining gaps in the epidemiological profile of these diseases and to determine risk factors for infection. In particular, molecular characterisation and detection of other markers should be conducted to determine the exact prevalence of viral hepatitis in this population.

\section{Abbreviations}

ART: Antiretroviral therapy; Cl: Confidence interval; ELISA: Enzyme-linked immunosorbent assay; HBsAg: Hepatitis B surface antigen; HBV: Hepatitis B; HCV: Hepatitis C; HCVAb: Hepatitis C antibody; HIV: Human immunodeficiency virus; RBC: Rwanda Biomedical Centre; SSA: Sub-Saharan Africa

\section{Acknowledgements}

We acknowledge the work done by National Reference Laboratory technicians and district hospital staff collecting and testing all samples during this activity.

\section{Funding}

The study was funded by Rwanda Biomedical Centre

\section{Availability of data and materials}

The datasets analysed during the current study are maintained by Rwanda Biomedical Centre and are available from the corresponding author on reasonable request.

\section{Authors' contributions}

$J U$ as the principal author participated in all phases of data collection analysis, and manuscript writing. BS, DD, JDM, AM, SN participated in conception, design, and implementation of this study. BS made substantial contributions to the analysis of data and drafting the manuscript. JU, BS, AM, JDM, EJM, NF and SN have substantially contributed to the interpretation of data and manuscript writing. SN, EJM, NF revised critically the manuscript content. All authors approved the final version for publication.

\section{Competing interests}

The authors declare that they have no competing interests.

\section{Consent for publication}

Not applicable.

\section{Ethics approval and consent to participate}

For this secondary analysis of routinely collected data, ethical approval was waived by the Rwanda Ethics Committee.

\section{Publisher's Note}

Springer Nature remains neutral with regard to jurisdictional claims in published maps and institutional affiliations.

\section{Author details}

${ }^{1}$ HIV/AIDS \& STIs Diseases Division, Rwanda Biomedical Centre, Kigali, Rwanda. ${ }^{2}$ Clinton Health Access Initiative, Kigali, Rwanda. ${ }^{3}$ Centre for Infectious Disease Epidemiology and Research, University of Cape Town, Cape Town, South Africa. ${ }^{4}$ University of Rwanda, Kigali, Rwanda. ${ }^{5}$ Basel Institute for Clinical Epidemiology and Biostatistics, University Hospital Basel, Basel, Switzerland. ${ }^{6}$ Swiss Tropical and Public Health Institute, University of Basel, Basel, Switzerland.
Received: 22 November 2016 Accepted: 26 April 2017

Published online: 02 May 2017

\section{References}

1. Naghavi M, Wang H, Lozano R, Davis A, Liang X, Zhou M, Vollset S. Global, regional, and national age-sex specific all-cause and cause-specific mortality for 240 causes of death, 1990-2013: a systematic analysis for the Global Burden of Disease Study 2013. Lancet. 2015;385(9963):117-71.

2. Mokdad A, Lopez A, Shahraz S, Lozano R, Mokdad A, Stanaway J, Murray C, Naghavi M. Liver cirrhosis mortality in 187 countries between 1980 and 2010: a systematic analysis. BMC Med. 2014;12:145.

3. Rao V, Johari N, du Cros P, Messina J, Ford N, Cooke G. Hepatitis C seroprevalence and HIV co-infection in sub-Saharan Africa: a systematic review and meta-analysis. Lancet Infect Dis. 2015;15(7):819-24.

4. Matthews $P$, Geretti A, Goulder P, Klenerman P. Epidemiology and impact of HIV coinfection with hepatitis B and hepatitis $C$ viruses in sub-Saharan Africa. J Clin Virol. 2014;61(1):20-33.

5. Rotman $Y$, Liang T. Coinfection with hepatitis $C$ virus and human immunodeficiency virus: virological, immunological, and clinical outcomes. J Virol. 2009:83(15):7366-74.

6. Bonacini M, Louie S, Bzowej N, Wohl A. Survival in patients with HIV infection and viral hepatitis B or C: a cohort study. AIDS. 2004;18(15):2039-45.

7. Mohsen A, Easterbrook P, Taylor C, Portmann B, Kulasegaram R, Murad S, Wiselka M, Norris S. Impact of human immunodeficiency virus (HIV) infection on the progression of liver fibrosis in hepatitis $C$ virus infected patients. Gut. 2003:52(7):1035-40.

8. Smith C, Ryom L, Weber R, Morlat P, Pradier C, Reiss P, Kowalska J, de Wit S, Law M, el Sadr W, Kirk O, Friis-Moller N, d'Arminio Monforte A, Phillip A, Sabin C, Lundgren J. Trends in underlying causes of death in people with HIV from 1999 to 2011 (D:A:D): a multicohort collaboration. Lancet. 2014;384(9939):241-8.

9. Lemoine M, Nayagam S, Thursz M. Viral hepatitis in resource-limited countries and access to antiviral therapies: current and future challenges. Futur Virol. 2013:8(4):371-80.

10. Wang H, Wolock T, Carter A, Nguyen G, Kyu H, Gakidou E, Hay S, Mills E, Trickey A, Msemburi W, Coates M, Mooney M. Estimates of global, regional, and national incidence, prevalence, and mortality of HIV, 1980-2015: the Global Burden of Disease Study 2015. Lancet HIV. 2016:3(8):e361-87.

11. Stabinski L, O'Connor S, Barnhart M, Kahn R, Hamm T. Prevalence of HIV and hepatitis B virus co-infection in sub-Saharan Africa and the potential impact and program feasibility of hepatitis B surface antigen screening in resourcelimited settings. J Acquir Immune Defic Syndr. 2015;68(Suppl 3):S274-85.

12. Azevedo $T$, Zwahlen $M$, Rauch A, Egger M, Wandeler $G$, et al. J Int AIDS Soc. 2016;19(1):20711.

13. Rusine J, Ondoa P, Asiime-Kateera B, Boer K, Uwimana J, Mukabayire O, Zaaijer H, Mugabekazi J, Reiss P, van de Wijgert J, et al. PLoS One. 2013:8(5):e63303.

14. Pirillo M, Bassani L, Germinario E, Mancini M, Vyankandondera J, Okong P, Vella S, Giuliano M. Seroprevalence of hepatitis B and C viruses among HIV-infected pregnant women in Uganda and Rwanda. J Med Virol. 2007:79(12):1797-801.

15. Suthar A, Harries A, et al. PLoS Med. 2015;12(3):e1001795.

16. Ford N, Singh K, Cooke G, Mills E, von Schoan-Angerer T, Kamarulzaman A, du Cros $P$. Expanding access to treatment for hepatitis $C$ in resource-limited settings: lessons from HIV/AIDS. Clin Infect Dis. 2012;54(10):1465-72.

17. Nsanzimana S, Kirk C, Uwizihiwe J, Bucher H. Increasing access to hepatitis $C$ treatment in Rwanda: the promise of Rwandas existing HIV infrastructure. Infect Dis Ther. 2015:3:245.

18. Nayagam S, Thursz M, Sicuri E, Conteh L, Wiktor S, Low-Beer D, Hallett T. Requirements for global elimination of hepatitis B: a modelling study. Lancet Infect Diseases. 2016;S1473-3099(16):30204-3.

19. Zampino R, Boemio A, Sagneli C, Alessio L, Adinolfi L, Sagnelli E, Coppola N. Hepatitis B virus burden in developing countries. World J Gastroenterol. 2015;21(42):11941-53.

20. Pippi F, Bracciale L, Stolzuoli L, Giaccherini R, Montomoli E, Gentile C, Filetti S, De Luca A, Cellesi C. Serological response to hepatitis $B$ virus vaccine in HIV-infected children in Tanzania. HIV Med. 2008:9(7):519-25.

21. Njom Nlend A, Nguwoh P, Ngounouh C, Tchidjou H, Pieme C, Otele J, Penlap V, Colizzi V, Moyou R, Fokam J. HIV-infected or exposed children exhibit lower immunogenicity to hepatitis B vaccine in Yaounde, Cameroon: an appear for revised policies in tropical settings? PLoS One. 2016;11(9):e0161714. 
22. Honge B, Jespersen S, Medina C, da Silva Te D, Lewin S, Ostergaard L, Laursen A, Krarup H, Erikstrup C, Wijse C. Hepatitis C prevalence among HIV-infected patients in Guinea-Bissau: a descriptive cross-sectional study. Int J Infect Dis. 2014;28:35-40.

23. Newton O, Oghene O, Okonko I. Anti-HCV antibody among newly diagnosed HIV patients in Ughelli, a suburban area of Delta state Nigeria. Afr Health Sci. 2015;15(3):728-36.

24. Bouare N, Gothot A, Delwaide J, Bontems S, Vaira D, Seidel L, Gerard P, Gerard C. Epidemiological profiles of human immunodeficiency virus and hepatitis C virus infections in Malian women: risk factors and relevance of disparities. World J Hepatol. 2013;5(4):196-205.

25. Harania R, Karuru J, Nelson M, Stebbing J. HIV, hepatitis B and hepatitis C coinfection in Kenya. AIDS. 2008;22(10):1221-2

26. Reilley B, Leston J, Hariri S, Neel L, Rudd M, Galope M, Ward J, Vellozzi C. Birth cohort testing for hepatitis C virus - Indian Health Service 2012-2015. MMWR. 2016;65(18):467-9.

27. Rein D, Smith B, Wittenborn J, Lesesne S, Wagner L, Roblin D, Patel N, Ward J, Weinbaum C. The cost-effectiveness of birth-cohort screening for hepatitis $C$ antibody in U.S. primary care settings. Ann Intern Med. 2012;156:4.

28. Coward S, Leggett L, Kaplan G, Clement F. Cost-effectiveness of screening for hepatitis $C$ virus: a systematic review of economic evaluations. BMJ Open. 2016;6(9):e011821.

29. Bruggmann P, Negro F, Bihl R, Blach S, Lavanchy D, Muellhaupt B, Razavi H, Semela D. Birth cohort distribution and screening for viraemic hepatitis $C$ virus infections in Switzerland. Swiss Med Wkly. 2015;145:W14221.

30. Mullis C, Laeyendecker O, Reynolds S, Ocama P, Quinn J, Boaz I, Gray R, Kirk G, Thomas D, Quinn T, Stabinski L. High frequency of false-positive hepatitis C virus enzyme-linked immunosorbent assay in Rakai, Uganda. Clin Infect Dis. 2013;57(12):1747-50

31. Graham C, Swan T. A path to eradication of hepatitis C in low- and middle-income countries. Antivir Res. 2015;119:89-96.

32. Seremba E, Ocama P, Opio C, Kagimu M, Thomas D, Yuan H, Attar N, Lee W. Poor performance of hepatitis $C$ antibody tests in hospital patients in Uganda. J Med Virol. 2010;82(8):1371-8.

33. Forbi J, Purdy M, Campo D, Vaughan G, Dimitrova Z, Ganova-Raeva L, Xia G, Khudyakov Y. Epidemic history of hepatitis $C$ virus infection in two remote communities in Nigeria, West Africa. J Gen Virol. 2012;93(7):1410-21.

34. Layden J, Phillips R, Opare-Sem O, Akere A, Salako B, Nelson K, Dugas L, Luke A, Tayo B, Cooper R. Hepatitis C in sub-Saharan Africa: urgent need for attention. Open Forum Infect Dis. 2014;1:2.

\section{Submit your next manuscript to BioMed Central and we will help you at every step:}

- We accept pre-submission inquiries

- Our selector tool helps you to find the most relevant journal

- We provide round the clock customer support

- Convenient online submission

- Thorough peer review

- Inclusion in PubMed and all major indexing services

- Maximum visibility for your research

Submit your manuscript at www.biomedcentral.com/submit

C) Biomed Central 